SEÇÃO

RESENHAS 
Nesta vida, pode-se aprender três coisas de uma criança: estar sempre alegre, nunca ficar inativo e chorar com força por tudo aquilo que se quer.

Paulo Leminski

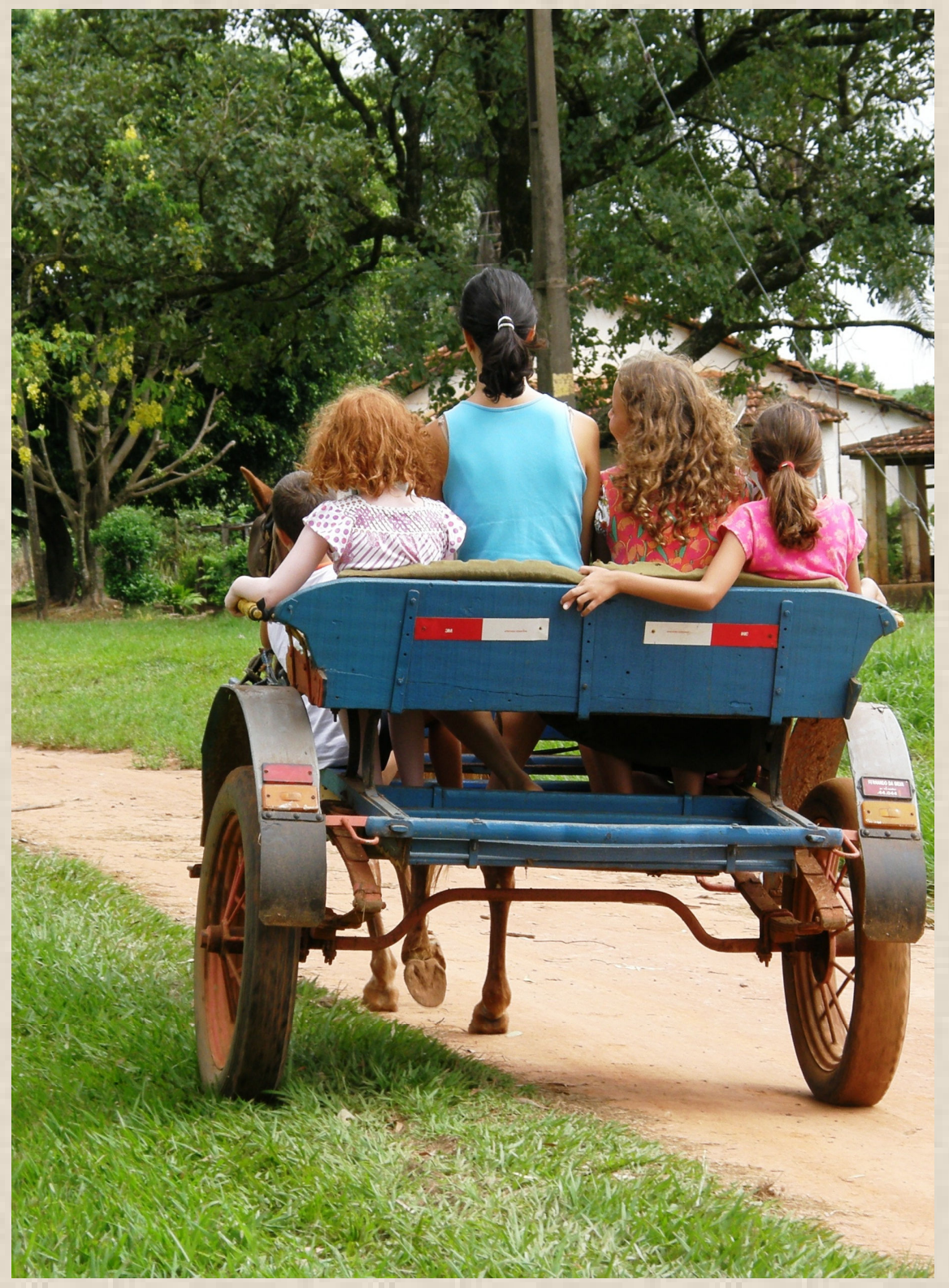




\section{Da parceria entre mestres e estudantes, novas interpretações sobre turismo e meio ambiente no Brasil}

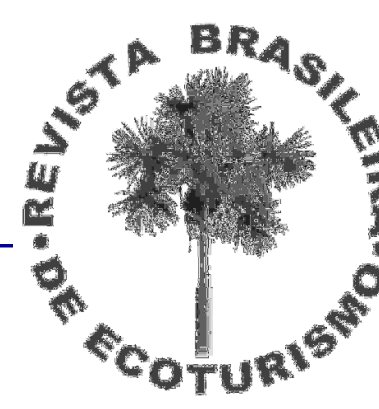

\section{Thiago Allis}

Neiman, Z.; Rabinovici, A. (orgs). Turismo e Meio Ambiente no Brasil. Barueri: Ed. Manole, 2010.

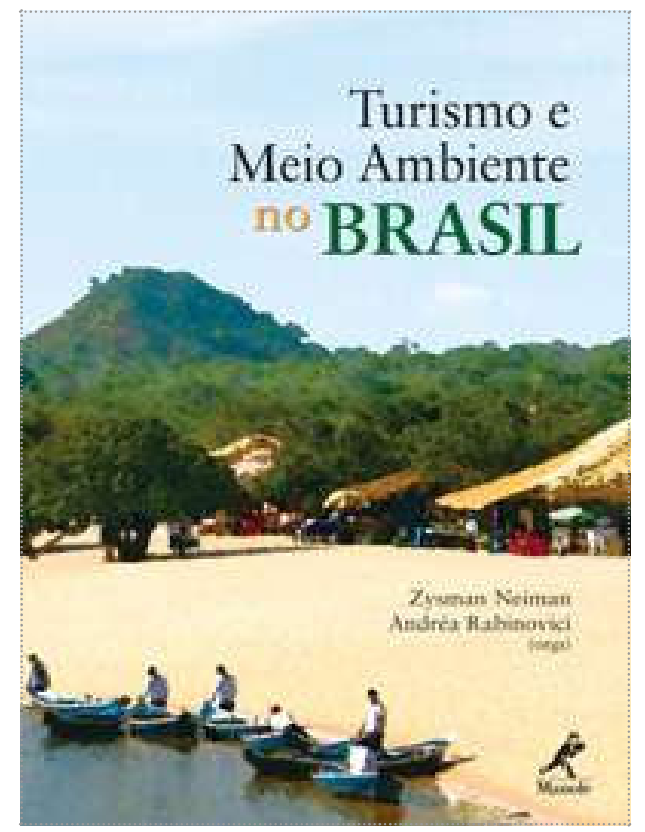

Tanto quanto poderia parecer óbvio, Turismo e meio ambiente no Brasil enceta uma discussão ampla e atualizada no ambiente acadêmico brasileiro, que ainda carece de boas e refrigeradas reflexões. Não que o binômio seja ausente nas últimas décadas (aliás, o seu contrário!), no entanto, parece haver lacunas de argumentações que sejam, a um só tempo, críticas e, sem serem rasteiras, assimiláveis na sua complexidade por um grande público.

Esta publicação é um bom sinal, conquanto vem recheada de impressões contundentes de discentes e docentes originários de uma universidade pública brasileira. Sem julgamentos levianos ou ufanistas, trata-se de um sintoma positivo da participação das instituições federais de ensino superior na construção do saber turístico no Brasil, consoan-

te com o aumento, nos últimos anos, da oferta de cursos de turismo nessas universidades.

Há uma interrogação que parece basal para o livro: questiona-se o turismo pelo prisma de um desenvolvimento econômico ad eternum. Nesse âmbito, já no capítulo um, são discutidas as dimensões de sustentabilidade vis-à-vis os paradigmas desenvolvimentistas e o advento do ambientalismo na vida contemporânea, aí incluído o turismo.

Como os próprios autores sugerem, esta espécie de incômodo original perpassa as discussões presentes em todo o livro - talvez este seja mesmo o pano fundo para sua construção, sendo que, da relação conceitual e prática do turismo com os temas ambientais, poderiam emergir respostas interessantes no caminho da sustentabilidade.

A relação do turismo com alguns temas é explícita: Unidades de Conservação, educação ambiental e participação das comunidades, mas outros temas também recebem atenção - e não por serem menos importantes: certificação e marketing de empresas e procedimentos, a questão indígena, elementos sustentáveis de projetos turísticos, políticas públicas de turismo no Brasil, dentre outros. Os conteúdos dos 
capítulos se tocam, mas, em absoluto, há sobreposições ou rupturas lógicas que inviabilizem uma leitura fluída.

Interessante é que o livro consegue, sem se desarticular, propor uma leitura temática, ou seja, estudos de tópicos específicos abordados nos vários capítulos. Por exemplo, as questões de base para o tratamento da relação turismo e meio ambiente podem ser encontradas nos capítulos um, dois e quinze (sendo este uma provocação para a manutenção das discussões finda a leitura); aqueles que buscam um estudo específico sobre a relação entre áreas protegidas e turismo têm boas referências nos capítulos cinco e sete; para se estudar a participação das comunidades na atividade turística, os capítulos seis e onze (sendo este focado nos territórios indígenas); do ponto de vista institucional e organizacional do turismo, os capítulos nove, dez, doze e treze sugerem uma unidade ao tratar das políticas de ecoturismo no Brasil e questões corporativas (como marketing e certificação).

Além das questões pungentes de conteúdo, a constituição do livro confirma seu caráter inovador. Trata-se de conceber, conduzir e trazer a público um forma de produção compartilhada no ambiente universitário, em que pese a participação de graduandos de um curso de turismo jovem de uma universidade pública veterana, a Universidade Federal de São Carlos. Para os estudantes, é uma oportunidade ímpar de, efetivamente, exercitar sua capacidade reflexiva, ainda na graduação, e já no contato com o público - fazendo frente a algo que recorrentemente se critica nas universidades públicas: produção de conhecimento de excelência sem o devido compartilhamento com a sociedade que lhe é mantenedora. Note-se que tudo isso acontece enquanto ainda estão em seu processo formativo, de tal sorte que, seguindo ou não carreiras acadêmicas, têm uma experiência de produção universitária bastante intensa, ademais daquelas que tradicionalmente desenvolvem no curso. Para os coordenadores, é de se supor a magnitude do esforço de, primeiro, convergir (e manter) interesses, canalizar capacidades de análise do grupo e, por fim, garantir uma forma palatável aos textos e, principalmente, conteúdos que atentem à responsabilidade a que o livro se propõe - servir de referência para o ensino e aprendizagem do turismo.

Há elementos de formato que são interessantes aparecerem numa publicação brasileira, especialmente em se tratando do mercado bibliográfico de turismo. A primeira é a inserção de quadros ao longo do texto (extraídos de sites, outros livros e revistas), que estimula vínculos mais fortes com a realidade do turismo no Brasil, além de comunicar pontos de vista e experiências de outras fontes - em suma, servem como hiperlinks para outras referências de pesquisa e informação.

Ademais, as questões para reflexão ao final dos capítulos instrumentalizam exercícios futuros relacionados ao tema, facilitando, pois, a utilização do livro como material didático. No que tange a essas questões, porém, cabe um alerta, especialmente àqueles que estamos envolvidos com estudos de ciências sociais aplicadas e o turismo em si: as perguntas sugeridas pressupõem, no geral, respostas do tipo binário ou excludentes (sim e não), o que, em se tratando da área estudada (turismo e meio ambiente) é algo questionável, posto que as gradações e possibilidades entre os extre- 
mos também podem ser construtivas; observa-se ainda uma leve retórica, que, no geral, levam o leitor a responder aquilo que se argumentou no capítulo que acabou de ler.

Algo que suscita inquietude - e não está suficientemente explicado pelos textos do livro - diz respeito à ênfase que se dá ao ecoturismo. É fato que, por mais que o estudo, a pesquisa e o ensino do turismo acumulem décadas de experiência, há uma multiplicidade de conceitos por se fazer e a prática turística ainda é razão de conflitos entre visitantes e visitados, especialmente no seu rebatimento territorial. Mesmo assim, já é tempo de se aceitar que a relação em turismo e meio ambiente vai muito além do ecoturismo praticado em ambientes naturais - haja vista que, num mundo em forte urbanização, a vida nas cidades deve ser entendida como fato e, neste sentido, relacioná-la com as possibilidades de desenvolvimento turístico.

Por que ecoturismo, educação ambiental e sustentabilidade quase sempre são tratados em face dos paradigmas convencionais de natureza? Não teríamos cidades ecoturísticas? Ou dito de outra maneira: o ecoturismo não é possível fora dos ambientes naturais? As comunidades urbanas não são, no seu ambiente urbano, parte do desafio da sustentabilidade? Se o ecoturismo é, conforme sugere o livro, uma estratégia promissora para a consecução das formas de turismo alternativo, é razoável que tentemos, pois, materializá-lo, conceitual e operacionalmente, em todos os ambientes da vida contemporânea - e não apenas em ou no entorno de Unidades de Conservação, em comunidades indígenas, em grupos de educação ambiental em áreas naturais, etc. Essas perguntas são tão mais importantes quando consideramos que, em linhas gerais, o turismo é um fenômeno essencialmente urbano, que emergiu quando do aprofundamento da urbanização e da sociedade industrial a partir do século XIX.

Portanto, mesmo que estejamos falando de ambientes intocados (se é que isso é possível!), a dialética entre urbano e não-urbano deveria ser o fulcro central das discussões: turistas são, essencialmente, das cidades, e, por isso, a lógica urbana está presente em tudo o que fazem atualmente - inclusive ecoturismo.

Seria um esforço em vão ou até mesmo ingênuo acreditar que as atividades turísticas, de base sustentável, poderiam se dar pelo combate à urbanidade, como sendo esta uma representação de um desenvolvimento econômico incompatível com o turismo sustentável. Ainda que esses dois mundos sejam vistos como antagônicos, há uma coexistência que se materializa por seus sujeitos: o ecoturista - instado a refletir sobre questões ambientais, partícipe de atividades de educação ambiental, visitante de comunidades tradicionais bastante diferente do seu modo de vida - continua sendo urbano e operador de um sistema produtivo intensivo de recursos naturais. Talvez, ser/estar ecoturista, seja apenas uma forma para a construção de uma nova consciência ambiental - mas, certamente, não a única.

Do ponto de vista de conceitos (ou, pelo menos terminologia), há, no decorrer dos textos e nas discussões de argumentos, uma alternância entre o uso de "ecoturismo" e "atividades turísticas", assim como "responsável" e "sustentável". Sabemos bastante bem que estas expressões comportam substratos conceituais distintos, 
mas é possível que seu uso indistinto nos textos reflita a indefinição de conteúdo ou sua complexidade na aplicação prática, daí porque, supõe-se, os autores optarem por discutir suas várias nuances de maneira quase sinonímica.

Com efeito, deve-se reconhecer que os significados de ecoturismo não estão exclusivamente vinculados a ambientes naturais (protegidos, sob a forma de Unidades de Conservação, ou não), no seu sentido mitológico e edênico. A obra sugere que o ecoturismo (em suas várias possibilidades, conforme discutido no capítulo três), seria a materialização do "turismo alternativo", em contraposição ao "turismo de massa".

Temos, além de todas as questões essenciais (consciência do visitante, participação comunitária, potencialidade de aprendizado durante a viagem, responsabilidades por parte dos empresários, etc.), uma questão de escala: é como se o volume e a intensidade do turismo de massa fossem, ao contrário do que se sugere com o ecoturismo, os responsáveis pela inviabilidade social e ambiental do turismo, em face de suas demandas econômicas.

O raciocínio é lógico e ganha eco nas críticas ao processo de expansão desenfreada da atividade a partir do terceiro quartel do século XX. No entanto, é premente que se incorpore em arenas como esta, de maneira lúcida e consistente, a questão comercial do turismo (para a qual é imprescindível a perspectiva do barateamento da produção em favor da lucratividade do negócio). Neste sentido, na obra, foram dados importantes espaços para esta temática, ao se tratarem, por exemplo, aspectos de responsabilidade social por parte das empresas e de marketing e certificação do turismo.

Houve, contudo, um viés levemente ideologizado da questão mercadológica, seja pelas convicções dos autores ou falta de opção na dinâmica turística contemporânea. Em certas passagens, flutua uma militância excessiva que, como é convencional, deveria ser contida em argumentações de fundo acadêmico e de corte científico.

Um exemplo disso são as assertivas de caráter apriorístico ao se propor formas de condução do turismo em face dos desafios da sustentabilidade. Por exemplo, não existem, pelo menos para o caso brasileiro, estudos profundos que confirmem que os turistas, de fato, estejam buscando experiências mais autênticas em detrimento do tão propalado turismo de massa - aliás, a julgar pela expansão do turismo na última década, pode-se inferir que o Brasil ainda vive sua fase extensiva (consolidação de grandes operadoras, inserção das classes média e baixa ao mercado turístico, políticas de turismo de caráter democratizantes, constituição de destinos turísticos em áreas menos tradicionais, etc.). A propósito de dados e para ficar no exemplo do ecoturismo, poucos são as estatísticas específicas, tanto de natureza quantitativa, quando qualitativa - daí porque ser, efetivamente, temeroso lançar observações taxativas sobre o mercado de ecoturismo no Brasil.

É importante frisar que esses aparentes dissensos não são deméritos ou pontos de inviabilidade da proposta do livro, senão elementos que emergem justamente por ocasião de sua publicação. Num processo de construção do conhecimento que preze pelo compartilhamento de ideias e pela incorporação de pontos de vista, é im- 
prescindível aceitar que as divergências são recursos para re-intepretações. Sendo o turismo campo de estudo relativamente recente e dadas as complexidades que envolve, é de desejar mesmo que as diferenças se multipliquem para que, num ambiente aberto, se pavimente com consistência o caminho para uma compreensão mais dilatada do fenômeno.

Neste sentido, a proposta de o livro ser uma obra didática merece atenção dos cursos de turismo e áreas afins, mas também das editoras que publicam tais temas, já que, num histórico de maturação do turismo como ensino superior, aquilo (e como) se produzia nos anos 1980 e 1990 no Brasil não só já tem um potencial reduzido de contribuição informativa e formativa, como deve vender bem pouco!

As perguntas que os autores se vão fazendo no decorrer de seus textos deveriam servir de estímulo para que todos estudiosos do turismo publicassem com mais frequência (em quaisquer meios), de maneira mais atraente e sempre comprometidos com a qualidade. Note-se que isso não implica prolixidade ou afetações, senão um compromisso em verter para a sociedade, de forma clara e criteriosa, novas inquietações a que vão sendo acometidos em suas pesquisas, estudos e outras experiências acadêmicas e profissionais.

Registre-se, por fim, o voto de confiança e, de certa forma, ousadia por parte de Editora Manole, que aceitou a proposta de publicar uma obra que, por mais que venha avalizada por dois pesquisadores de envergadura, pressupõe a abertura de espaço para iniciantes no estudo do turismo. E o faz de uma maneira bastante produtiva, pois, num só tempo e espaço, oportunizou a conversa de um grupo de estudantes (observados por mestres atentos) com os seus pares, ou seja, tantos milhares de estudantes de turismo e áreas afins no Brasil (ou, quem sabe, de países de língua portuguesa mundo afora).

Thiago Allis: Universidade Federal de São Carlos, câmpus Sorocaba.

Email: thiagoallis@ufscar.br

Link para o currículo Lattes: http://lattes.cnpq.br/8352597486424889

Data de submissão: 17 de maio de 2010.

Data de aceite: 21 de maio de 2010. 